\title{
MENTAL HEALTH LITERACY: A SYSTEMATIC REVIEW OF THE MEASUREMENT INSTRUMENTS
}

\author{
Cláudia Balula Chaves \\ Health Shcool, CI\&DEI, Polytechnic Institute of Viseu, Portugal, \\ cchaves@essv.ipv.pt \\ Carlos Sequeira \\ Nursing School of Porto, CINTESIS, Porto - Portugal, \\ carlossequeira@esenf.pt \\ João Carvalho Duarte \\ Health School, UICISA: E, Polytechnic Institute of Viseu, Portugal \\ duarte.johnny@gmail.com

\section{Paula Nelas} \\ Health School, UICISA: E, Polytechnic Institute of Viseu, Portugal \\ pnelas@gmail.com \\ Amadeu Gonçalves \\ Health School, CINTESIS, Polytechnic Institute of Viseu, Portugal \\ agoncalves@essv.jpv.pt \\ Eduardo Santos \\ Health School, UICISA: E, Polytechnic Institute of Viseu, Portugal \\ Portugal Centre for Evidence Based Practice (PCEBP): a JBI Centre of Excellence \\ ejf.santos87@gmail.com
}

Recepción Artículo: 27 agosto 2021 Admisión Evaluación: 07 septiembre 2021 Informe Evaluador 1: 12 septiembre 2021 Informe Evaluador 2: 13 septiembre 2021 Aprobación Publicación: 15 septiembre 2021

\section{ABSTRACT}

Background: Mental health literacy has become increasingly important as an empowerment tool in the field of mental health. Any intervention should always be preceded by a clear diagnosis of the situation. Objectives: To identify mental health literacy measurement instruments among adults living in a given community. Methods: An integrative review of the literature was conducted using the PICOD method by searching the following scientific databases: PubMed, SciELO, LILACS, MEDLINE, EBSCO, Cochrane Library and EMBASE. The JBI critical appraisal checklist for methodological quality was used and the PRISMA guidelines were taken into account to critically assess the quality of the studies included in this work. Three articles met the inclusion criteria and were therefore included in the study. Results: Three instruments for assessing mental health literacy were identified: the MHLS, the MHKQ and the MAKS. The assessment of the methodological and psychometric quality of each of these instruments demonstrated that one of the studies showed a very good level of reliability, another study showed an acceptable level of reliability, whereas the last one showed a poor level of reliability. Conclusion: 
These results show that the MHLS is the best validated assessment tool for health care professionals. Given the limited number of primary studies identified, the construction of an instrument to assess the level of positive mental health literacy in the community is crucial.

Keywords: health literacy; mental health; assessment instruments; community; adults; health promotion

\section{RESUMEN}

Alfabetización en salud mental: una revisión sistemática de los instrumentos de medición. Antecedentes: La alfabetización en salud mental ha adquirido una importancia creciente como herramienta de empoderamiento en el ámbito de la salud mental. Cualquier intervención debe ir siempre precedida de un diagnóstico claro de la situación. Objetivos: Identificar los instrumentos de medición de la alfabetización en salud mental entre los adultos que viven en una comunidad determinada. Métodos: Se realizó una revisión integradora de la literatura utilizando el método PICOD mediante la búsqueda en las siguientes bases de datos científicas: PubMed, SciELO, LILACS, MEDLINE, EBSCO, Cochrane Library y EMBASE. Se utilizó la lista de comprobación de la calidad metodológica del JBI y se tuvieron en cuenta las directrices PRISMA para evaluar críticamente la calidad de los estudios incluidos en este trabajo. Tres artículos cumplieron los criterios de inclusión y, por tanto, se incluyeron en el estudio. Resultados: Se identificaron tres instrumentos para evaluar la alfabetización en salud mental: el MHLS, el MHKQ y el MAKS. La evaluación de la calidad metodológica y psicométrica de cada uno de estos instrumentos demostró que uno de los estudios mostró un nivel de fiabilidad muy bueno, otro estudio mostró un nivel de fiabilidad aceptable, mientras que el último mostró un nivel de fiabilidad pobre. Conclusión: Estos resultados muestran que el MHLS es el mejor instrumento de evaluación validado para los profesionales de la salud. Dado el limitado número de estudios primarios identificados, es crucial la construcción de un instrumento para evaluar el nivel de alfabetización en salud mental positiva en la comunidad.

Palabras clave: alfabetización en salud; salud mental; instrumentos de evaluación; comunidad; adultos; promoción de la salud

\section{INTRODUCTION}

Mental health is defined as a general state of well-being in which every individual realises his/her own potential, can cope with life's adversities and is able to contribute to the development of his/her community (WHO, 2014). However, mental health should be much more than the absence of mental illness or disorders, i.e., it is a positive element, a resource with an intrinsic value, an important asset that contributes to physical health and quality of life, a universal foundation of individual well-being, and an essential condition for a person or for a community to achieve proper functioning, regardless of geographical or cultural factors (Quartilho, 2010; Gaino, Souza, Cirineu, \& Tulimosky, 2018). From this perspective, mental health is associated with the ability to adjust to new life circumstances, the capacity to overcome crises and solve emotional conflicts, to recognize limits, to develop critical and reality awareness, and to build satisfactory relationships with other individuals in the community (Portugal, MS, DGS, 2016b).

It should also be noted that positive mental health is intimately linked with the concept of quality of life, implying not only the satisfaction of basic and social needs, but also the autonomy and ability to interact civically and socially, as well as the ability to enjoy life (Quartilho, 2010). Mental health literacy defined as "the knowledge and beliefs about mental disorders that aid their recognition, management or prevention" (Jorm, 1997, p. 182) implies the provision of specific and necessary knowledge to take action, either for one's own health or for the health of those around him/her (Loureiro, 2014). It is composed of five components, as already mentioned, and focuses mainly on the empowerment of people to remove structural barriers to health (Public Health England, 2015), since low levels of mental health literacy, combined with social stigma and prejudice, lead to a decrease in professional help-seeking attitudes (Loureiro, 2014).

The development of mental health assessment instruments, standardised in accordance with the current criteria and taxonomies, is a resource used to collect and analyse data and decide what should or should not be 
included and that will, thus, be of assistance in any given decision-making process. Several instruments are described in health literature (Berkman, et al., 2011; Carvalho, Marin Rueda, 2016; Marques, \& Lemos, 2017), however, there are few instruments available that focus specifically on the issue under study (mental health literacy). On the other hand, the evidence available is often dispersed. Therefore, the aim of this study was to summarise the characteristics of the tools that already exist and that best assess mental health literacy among adults living in a given community. To this end, we designed the following research question: "Which are the existing instruments that best assess mental health literacy in adults living in a given community?

\section{METHODOLOGY}

This systematic review was conducted in accordance with the method suggested by the Joanna Briggs Institute (Stephenson, Riitano, Wilson, Leonardi-Bee, Mabire, Cooper, et al, 2020) and was written according to the Preferred reporting items for systematic reviews and meta-analyses (PRISMA) (Page, McKenzie, Bossuyt, Boutron, Hoffmann, Mulrow, et al, 2021). The review protocol was carried out and followed by the authors although it has not been published and/or registered. However, it can be sent upon request.

The location and selection of studies, carried out between January $2^{\text {nd }}$ and April $4^{\text {th }}, 2018$, comprised electronic searches conducted for title, abstract and subject, across pre-specified and comprehensive biomedical databases like US National Library of Medicine National Institutes of Health (PubMed), Scientific Electronic Library Online (SciELO), Latin American and Caribbean Literature on Health Sciences (LILACS) (via BVS), MEDLINE, EBSCO, Cochrane Library and EMBASE. Studies in English, Portuguese and Spanish were included, and no time limitations were set for the search. In order to confirm the health descriptors, we used the http://decs.bvs.br/ website and obtained a positive response for Health Literacy, Mental Health, Surveys and questionnaires and Health Knowledge, Attitudes, Practice. The search strategies applied are shown in Table 1. 
Table 1 - Search strategies

\begin{tabular}{|c|c|c|}
\hline Databases & Boolean equation & Results \\
\hline Pubmed & $\begin{array}{l}\text { "Health Literacy [Mesh Terms] AND Mental Health [Mesh Terms] } \\
\text { AND Surveys and Questionnaires [Mesh Terms]", "Mental Health } \\
\text { [Mesh Terms] AND Health Knowledge, Attitudes, Practice [Mesh } \\
\text { Terms] AND Surveys and Questionnaires [Mesh Terms]" and } \\
\text { "Health Literacy [Mesh Terms] AND Mental Health [Mesh Terms] } \\
\text { AND Health Knowledge, Attitudes, Practice [Mesh Terms] AND } \\
\text { Surveys and Questionnaires [Mesh Terms]" }\end{array}$ & 149 \\
\hline SciELO & $\begin{array}{l}\text { "Surveys and Questionnaires AND Health Literacy AND Mental } \\
\text { Health AND Health Knowledge, Attitudes, Practice" [All indexes], } \\
\text { "Health Literacy AND Mental Health AND Surveys and } \\
\text { Questionnaires" [All indexes], "Mental Health AND Health } \\
\text { Knowledge, Attitudes, Practice AND Surveys and Questionnaires" } \\
\text { [All indexes], "Mental Health AND Surveys and Questionnaires" } \\
\text { [All indexes], "Salud Mental AND Encuestas y Cuestionarios" [All } \\
\text { indexes] and "Saúde Mental AND Inquéritos e Questionários" [All } \\
\text { indexes] }\end{array}$ & 392 \\
\hline LILACS & $\begin{array}{l}\text { "Mental Health AND Surveys and Questionnaires" [Title, abstract, } \\
\text { subject], "Salud Mental AND Enquestas y Cuestionarios" [Title, } \\
\text { abstract, subject] and "Saúde Mental AND Inquéritos e } \\
\text { Questionários" [Title, abstract, subject]. }\end{array}$ & 86 \\
\hline Medline & $\begin{array}{l}\text { "Health Literacy [Mesh Terms] AND Mental Health [Mesh Terms] } \\
\text { AND Surveys and Questionnaires [Mesh Terms]", "Mental Health } \\
\text { [Mesh Terms], Health Knowledge, Attitudes, Practice [Mesh } \\
\text { Terms] AND Surveys and Questionnaires [Mesh Terms]", "Health } \\
\text { Literacy [Mesh Terms] AND Mental Health [Mesh Terms] AND } \\
\text { Health Knowledge, Attitudes, Practice [Mesh Terms] AND } \\
\text { Surveys and Questionnaires [Mesh Terms]" }\end{array}$ & 281 \\
\hline Cochrane Library & $\begin{array}{l}\text { "mh Mental Health AND mh Health Knowledge, Attitudes, } \\
\text { Practice AND mh Surveys and questionnaires AND mh Health } \\
\text { Literacy", "mh Health Literacy AND mh Mental Health ANDmh } \\
\text { Surveys and questionnaires", "mh Mental Health AND mh Health } \\
\text { Knowledge, Attitudes, Practice AND mh Surveys and } \\
\text { questionnaires" and "mh Mental Health AND mh Surveys and } \\
\text { questionnaires" }\end{array}$ & 747 \\
\hline EBSCO & $\begin{array}{l}\text { "(MH "Mental Health") AND (MH "Health Knowledge, Attitudes, } \\
\text { Practice") AND (MH "Surveys and Questionnaires")", "(MH } \\
\text { "Mental Health") AND (MH "Health Literacy") AND (MH } \\
\text { "Surveys and Questionnaires")" and "(MH "Mental Health") AND } \\
\text { (MH "Health Literacy") AND (MH "Surveys and Questionnaires") } \\
\text { AND (MH "Health Knowledge, Attitudes, Practice") }\end{array}$ & 390 \\
\hline EMBASE & $\begin{array}{l}\text { exp Health Literacy/ AND exp Mental Health/ AND exp Attitude } \\
\text { to Health/ AND exp Questionnaires/", "exp Health Literacy/ } \\
\text { AND exp Mental Health/ AND exp Questionnaires/" and "exp } \\
\text { Mental Health/ AND exp Attitude to Health/ AND } \\
\text { exp Questionnaires/" }\end{array}$ & 274 \\
\hline
\end{tabular}

The following inclusion criteria were considered:

- Population/Participants (P): Studies that include adults (age 18 years or older);

- Instruments (I): Studies that use assessment instruments to assess mental health literacy;

- Context (C): Only studies carried out in the community;

- Outcomes/Results (0): Studies focusing on assessment instruments that show the best psychometric results;

- Design (D): Primary quantitative studies 
Once the search was over, all identified citations were transferred to Endnote V7.7.1 (Clarivate Analytics, PA, USA) and duplicates were removed. In order to assess their eligibility, the titles and abstracts were analysed by two independent reviewers. Failing consensus, a third reviewer was included as a tie breaking criterion. Endnote V7.7.1 was also used as a tool to record the single-blind peer reviews conducted. Once the duplicates are removed, the articles were distributed among the reviewers for independent selection and after this procedure the articles were reconciled so that the concordance of the selection could be analysed. After this, the articles were read in full, and the inclusion criteria mentioned above were applied.

Two researchers were involved in this process to independently classify the studies found, and thus minimise assessment errors caused by individual idiosyncrasies (Varandas \& Carneiro, 2006). Failing consensus, a third reviewer (ES) was included as a tie breaking criterion. In order to critically assess the quality of the studies selected, the JBI critical appraisal checklist for analytical cross-sectional studies was used. Quality studies were thus included, i.e., those which obtained no more than two negative responses (JBI, 2017). Additionally, we used the COSMIN Risk of Bias checklist (Mokkink, de Vet, Prinsen, Patrick, Alonso, Bouter, \& Terwee, 2018) to analyse the methodological quality of each psychometric property. This tool considers that each property can be considered as very good, adequate, doubtful, or inadequate.

It should be noted that the quality assessment, data extraction and synthesis were performed by two researchers individually and that failing consensus a third one was brought in as a tie breaking criterion. During data extraction, a data collection instrument specially designed by the authors was used to reduce the risk of bias. In the end, the results were grouped in an evidence framework and a narrative synthesis was performed.

\section{RESULTS}

The first selected sample was composed of 2319 studies. Limiters were applied to narrow the focus of the search so that only studies that met the following requirements were considered: quantitative studies, published in Portuguese, Spanish or English, studies published between January 2013 and December 2017, studies conducted with adults, and studies conducted with human subjects. Once duplicates were removed, our sample dropped to 1178, as 1141 studies were excluded. Then, we went on with the analysis by reading the titles and abstracts of the articles retrieved according to the rigorous set of criteria previously presented to refine the corpus study. The following flowchart representing those different stages was designed to provide a clearer, more precise and objective reading of the steps that composed the study refinement process. 
Figure 1 - Flowchart representing the stages of refinement of the study corpus.

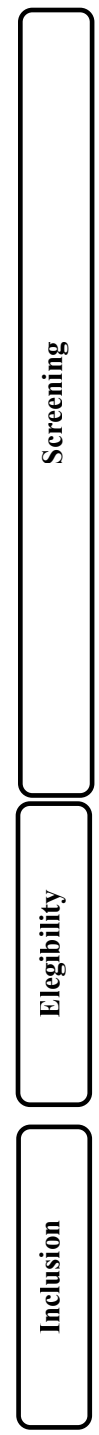

Total item retrieved $(\mathrm{n}=2319)$
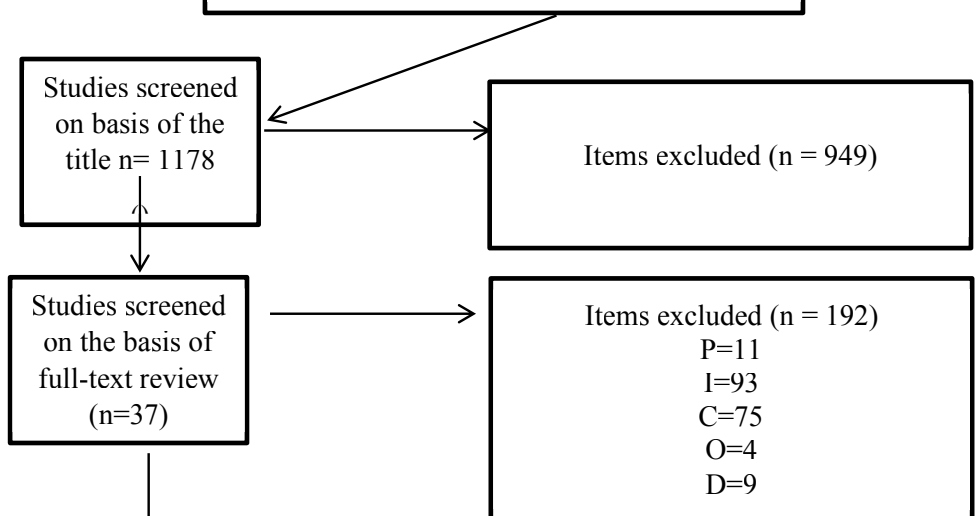

Items excluded $(\mathrm{n}=34)$
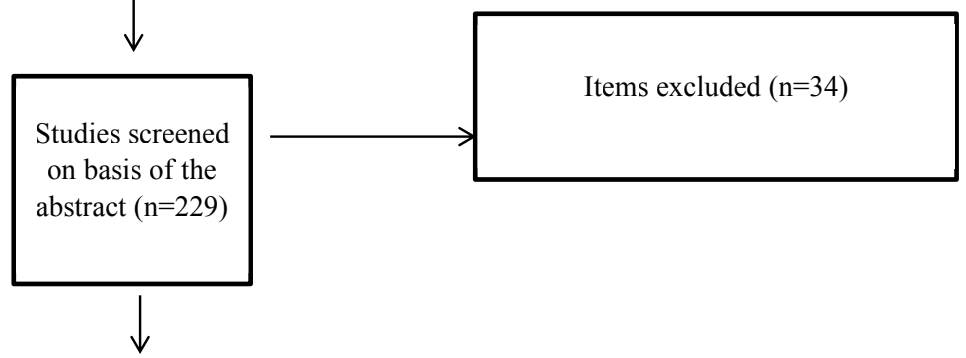

Studies included

in qualitative

synthesis $(n=3)$

The studies included in this research are described in Table 2 and the results of the methodological quality assessment are displayed in Table 3. 
Table 2 - Articles included in the review

\begin{tabular}{|c|c|c|}
\hline Study & Author(s) & Title \\
\hline I & $\begin{array}{l}\text { O'Connor, M., \& Casey, } \\
\text { L., } 2015\end{array}$ & $\begin{array}{l}\text { The Mental Health Literacy Scale (MHLS): A new } \\
\text { scale-based measure of mental health literacy }\end{array}$ \\
\hline II & $\begin{array}{l}\text { Wang, J., He, Y., Jiang, } \\
\text { Q., Cai, J., Wang, W., } \\
\text { Zeng, Q., .. Zhang, M., } \\
2013\end{array}$ & Mental health literacy among residents in Shanghai \\
\hline III & $\begin{array}{ll}\text { Hansson, } & \text { L., } \\
\text { Stjernsward, } & \text { S., } \\
\text { Svensson, B., 2016 } & \\
\end{array}$ & $\begin{array}{l}\text { Changes in attitudes, intended behaviour, and mental } \\
\text { health literacy in the Swedish population } 2009-2014 \text { : } \\
\text { an evaluation of a national antistigma programme }\end{array}$ \\
\hline
\end{tabular}

As referred before, once the selection of studies was completed, and duly identified, three analytical crosssectional studies were selected.

Study I - The Mental Health Literacy Scale (MHLS): A new scale-based measure of mental health literacy. (0'Connor \& Casey, 2015)

This is an analytical cross-sectional study whose purpose is to assess individuals' level of mental health literacy. It offers a new quantitative measurement scale, the MHLS, that follows a sequence of methodological criteria.

The construction of the MHLS was carried out over three key stages, including measure development, pilot testing and assessment of psychometrics and methodological quality.

In the first phase of development, the MHLS-P consisted of 79 items included in a Likert-type scale. This first version was administered to a community sample composed of 202 participants (62 men vs. 140 women) to conduct a preliminary analysis of the items included. Participants were between 18 and 80 years old, with a mean age of $33.25 \pm 16.02$ years. The majority (185) of the participants were Caucasian (91.8\%), 109 of the respondents had at least a bachelor's degree (54\%), and 161 of them were living in a large city $(79.7 \%)$.

Data analysis was conducted using the SPSS software version 17.0. Following the statistical analysis, the MHLS-P was refined and led to the design of the MHLS-P-R, which resulted in a total of 51 items. 21 of those items referred to the ability to recognise disorders, 4 to knowledge and attitudes about where to seek information, 2 to knowledge of risk factors and causes, 2 to knowledge of self-treatment, 5 to knowledge of professional help available and 17 to attitudes that promote recognition and appropriate help-seeking behaviours.

In order to further refine the MHLS-P-R and assess its psychometric validity, this version was administered to a sample consisting of 415 participants. 372 were first-year university students with no background in mental health (94 males vs. 278 females), and 43 were mental health professionals ( 6 males vs. 37 females). The mean age of the university students was $21.10 \pm 6.27$ years, whereas the mean age of the health professionals was $33.09 \pm 8.01$ years. 274 of the 372 university students were Caucasian $(73.7 \%), 283$ of them had a secondary school certificate (76.1\%) and 283 lived in a major city (76.1\%). 37 of the 43 health professionals were Caucasian (86\%), 41 had at least a bachelor's degree (95.4\%) and 38 were living in a large city (88.4\%).

In order to increase the reliability of the measurement instrument, items with an item-total correlation coefficient less than 0.2 were removed. The final version, then called MHLS, was composed of a total of 35 items. 8 of these items referred to the ability to recognise disorders, 4 to knowledge and attitudes about where to seek information, 2 to knowledge of risk factors and causes, 2 to knowledge of self-treatment, 3 to knowledge of professional help available and 16 to attitudes that promote recognition or appropriate help-seeking behaviours.

Study II - Mental health literacy among residents in Shanghai (Wang et al., 2013)

The study was conducted in all 19 districts of Shanghai, China, from September to November 2011 and 1953 residents in these districts aged 15 years or older were randomly sampled. 996 of these 1953 participants were male (51.0\%) and 957 were female (49.0\%). The mean age of the participants was $50 \pm 17$ years, and 476 of them were under 35 years of age (24.4\%), 1132 were between 35 and 64 years of age (58.1\%), and 340 were 65 years 
or older (17.5\%). As for the participants' level of education, 277 had an elementary school education or less (14.2\%), 1137 had completed high school (58.2\%) and 539 had a college education (27.6\%). 263 of the participants were single (13.5\%), 1567 were married (80.2\%) and 123 were divorced, separated, or widowed (6.3\%).

This was an analytical cross-sectional study whose objective was to assess the mental health literacy of the residents of those districts. This study uses two subscales from the Mental Health Work Questionnaire developed in 2009 by the Chinese Ministry of Health: the Mental Health Knowledge Questionnaire (MHKQ) and the Case Assessment Questionnaire (CAQ). However, in line with the formulated research question, only the MHKQ will be addressed, as it is the only assessment instrument whose psychometric properties are clearly defined.

The MHKQ is composed of 20 items: items 1 through 16 assess general knowledge about mental health issues, while items 17 to 20 assess the participants' awareness of the existence of four mental health promotion days. In items 1 through 16, participants have three response options, namely "true", "false" or "unknown". In items 17 to 20 the response options are only "yes" and "no". One point is given to each correct answer, while incorrect answers or "unknown" responses scored zero points. That way, the total score ranges from 0 to 20 , with higher scores indicating better mental health literacy.

Data was analysed using SPSS software version 17.0. Descriptive statistics were presented for each item in the MHKQ. Its internal consistency was assessed using Cronbach's alpha values. In addition, t-tests and ANOVA with post-hoc tests (Bonferroni) were used to compare the participants' mental health literacy score and the participants' general identification scores by gender (male vs. female), age group ( $<35$ years old vs. $>35$ years old), level of education (middle school or less vs. high school vs. college) and marital status (currently married vs. not currently married).

Study III - Changes in attitudes, intended behaviour, and mental health literacy in the Swedish population 2009-2014: an evaluation of a national antistigma programme (Hansson, Stjernswärd, \& Svesnsson, 2016)

The study was conducted in Sweden from 2009 to 2014 to implement antistigma campaigns in different three regions. The campaigns were carried out in 2010 and 2014 and aimed at investigating changes in mental health literacy, attitudes towards people with mental illness and stigma during this period as compared to baseline in 2009. Two separate yearly data collections were conducted one including a nationally representative sample and one which included a sample from the three regions. Participants were randomly selected and the final sample for the national surveys ranged from 2053 to 2317 and the regional sample from 657 to 1153.

This is an analytical cross-sectional study in which the Mental Health Knowledge Scale (MAKS), an assessment instrument that corresponds to the research question, was applied.

The MAKS comprises 12 items. The first 6 items are related to stigma-related issues in several areas of mental health literacy, namely help-seeking, ability to give advice, support, employment, treatment and recovery, and the remaining 6 items assess knowledge of mental illness diagnoses. The items responses are rated on a 5-point scale, ranging from 1 ("strongly disagree") to 5 ("strongly agree") with the additional possibility of choosing the option "don't know".

Data was analysed using SPSS Version 21.0. To describe the characteristics of the population, a statistical analysis was performed using multiple linear regression to observe the changes that occurred between 2009 and 2014, both at national level and in the three campaign regions. Standardised B, confidence interval and p-values were used to ensure the final sample's representativity with regard to age, gender, level of education and familiarity with mental illness. 


\section{Table 3 - Studies included}

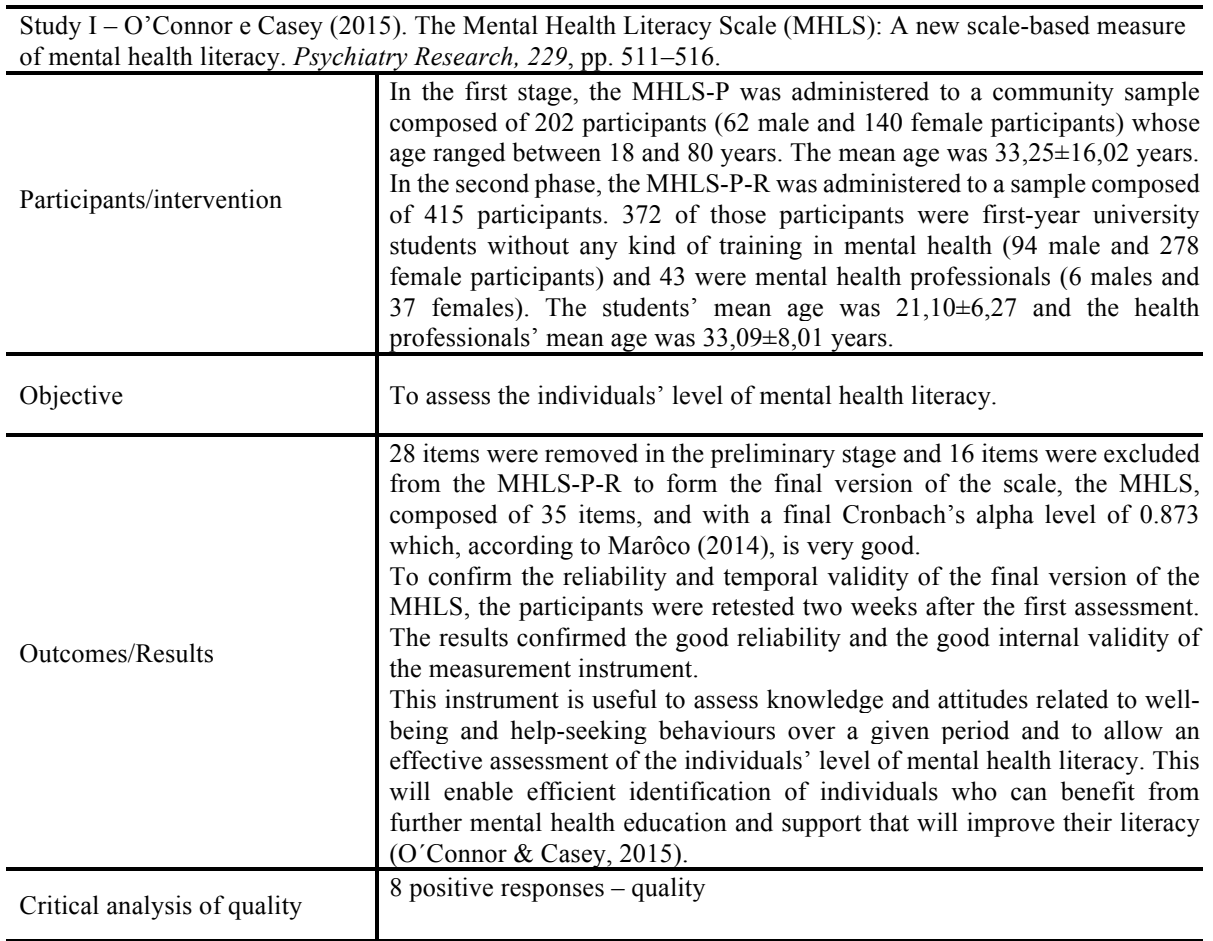

Study II - Wang et al. (2013). Mental health literacy among residents in Shanghai. Shanghai Archives of Psychiatry, 4, pp. 225-235. doi: 10.3969/j.issn.1002-0829.2013.04.004.

\begin{tabular}{l|l}
\hline \multirow{3}{*}{ Participants/intervention } & $\begin{array}{l}\text { Analytical cross-sectional study that included a random sample composed } \\
\text { of } 1953 \text { participants living in all } 19 \text { districts of Shanghai, China, and who } \\
\text { were } 15 \text { or older. Two subscales from the Mental Health Work } \\
\text { Questionnaire developed in } 2009 \text { by the Chinese Ministry of Health: the } \\
\text { Mental Health Knowledge Questionnaire (MHKQ) and the Case } \\
\text { Assessment Questionnaire (CAQ) were used. }\end{array}$ \\
\hline Objective & $\begin{array}{l}\text { To assess knowledge and attitudes about mental disorders among the } \\
\text { residents in all } 19 \text { districts of Shanghai, China. }\end{array}$ \\
\hline
\end{tabular}




\begin{tabular}{|c|c|}
\hline Outcomes/ Results & $\begin{array}{l}\text { Correct response rates for the } 20 \text { items of the MHKQ ranged from } 26.3 \text { to } \\
98.1 \% \text {. The mean correct response rate for the } 20 \text { items was } 71.9 \% \text {. That } \\
\text { way, the computed mental health literacy score ranged between } 6 \text { to } 20 \text { and } \\
\text { the mean value was } 14.4 \pm 3,1 \text {. The internal consistency, provided by } \\
\text { Cronbach's alpha, on the } 20 \text { items of the MHKL was } 0.69 \text {. However, it } \\
\text { dropped to } 0.59 \text { when the four items about mental health promotion days } \\
\text { were removed. This means, according to Pestana et Gageiro ( } 2008 \text { ), that } \\
\text { internal consistency went from fair to poor. To define sets of strongly } \\
\text { correlated items (factors), the authors performed an exploratory factor } \\
\text { analysis. Factors are used to reduce data to a smaller number of variables } \\
\text { without any significant loss of information. That way, the analysis of } 976 \\
\text { randomly selected surveys identified } 6 \text { factors with eigenvalues greater } \\
\text { than } 1 \text {, and accounted for } 50.3 \% \text { of the variance. } \\
\text { According to the authors, the exploratory factor analysis had essentially the } \\
\text { same result after the exclusion of the four items. Considering the scree plot } \\
\text { of the eigenvalues, the authors selected a } 5 \text {-factor model for the } 20 \text {-item } \\
\text { version of the scale as the best representation of the distinct constructs } \\
\text { considered in the scale. This model was tested in a confirmatory factor } \\
\text { analysis using the second half of the total sample of surveys (n=977). The } \\
\text { results of the confirmatory factor analysis accounted for } 45.1 \% \text { of the total } \\
\text { variance. Three of the factors ( } 1,2 \text { and } 5 \text { ) remained the same as in the } \\
\text { exploratory factor analysis. However, factors } 3 \text { and } 4 \text { were modified since } \\
\text { they migrated differently than in the exploratory factor analysis. As for the } \\
\text { surveys included in the confirmatory factor analysis, the internal } \\
\text { consistency of the original items included in factor } 1 \text { (Cronbach's alpha } \\
=0.73 \text { ) and factor } 2 \text { (Cronbach's alpha =0.60) were acceptable, but the } \\
\text { internal consistency of the original items included in factor } 3 \text { (Cronbach's } \\
\text { alpha =0.49), factor } 4 \text { (Cronbach's alpha =0.39) and in factor } 5 \\
\text { (Cronbach's alpha=0.42) were poor, according to Pestana et Gageiro } \\
\text { (2008) }\end{array}$ \\
\hline Critical analysis of quality & 8 positive answers - quality \\
\hline \multicolumn{2}{|c|}{$\begin{array}{l}\text { Study III - Hansson et al. (2016). Changes in attitudes, intended behaviour, and mental health literacy in the } \\
\text { Swedish population 2009-2014: an evaluation of a national antistigma programme. Acta Psychiatr Scand, } 134 \\
(446) \text {, pp. } 71-79 \text {. doi:10.1111/acps. } 12609 \text {. }\end{array}$} \\
\hline Participants/intervention & $\begin{array}{l}\text { Analytical cross-sectional study composed of a national random sample } \\
\text { that ranged between } 2053 \text { and } 2317 \text { and a regional sample that ranged from } \\
657 \text { to } 1153 \text {. Two yearly surveys were conducted: one of them included a } \\
\text { nationally representative sample and the other included a sample from the } \\
\text { three regions where an antistigma campaign had been implemented. Three } \\
\text { assessment instruments were administered: the Community Attitudes } \\
\text { toward Mental Illness (CAMI), the Reported and Intended Behaviour Scale } \\
\text { (RIBS) and the Mental Health Knowledge Scale (MAKS). }\end{array}$ \\
\hline Objective & $\begin{array}{l}\text { To implement antistigma campaigns in three regions between } 2010 \text { and } \\
2014 \text { to investigate changes in mental health literacy, in the attitudes } \\
\text { toward people suffering from mental illness and in stigma during this } \\
\text { period as compared to data from } 2009 .\end{array}$ \\
\hline
\end{tabular}




\begin{tabular}{l|l}
\hline & $\begin{array}{l}\text { The main conclusions of the study show that there have been significant } \\
\text { and positive changes in people's attitudes, in mental health literacy and } \\
\text { stigma during the campaign years. These conclusions are primarily evident } \\
\text { in the three regions where the campaign was launched in 2010, which } \\
\text { comprise about } 25 \% \text { of the Swedish population. At a national level, more } \\
\text { significant changes were evident as of 2012, when the campaign was } \\
\text { extended to five further regions comprising that way a further fourth of the } \\
\text { population. In general, higher levels of mental health literacy were found } \\
\text { among female participants, among younger participants and among those } \\
\text { who showed a higher degree of familiarity with mental illness. In the } \\
\text { campaign regions, in addition to the characteristics previously listed, } \\
\text { people with higher education demonstrate higher levels of mental health } \\
\text { literacy. The overall internal consistency of the Mental Health Knowledge } \\
\text { Scale (MAKS) was found acceptable (Cronbach's alpha between } 0.67 \text { and } \\
0.71) \text { The questionnaire has showed good psychometric properties with } \\
\text { regard to reliability and validity. }\end{array}$ \\
\hline Critical analysis of quality & 8 positive answers - quality \\
\hline
\end{tabular}

\section{DISCUSSION}

Based on the information obtained from the three studies retrieved, it is impossible to predict whether or not the assessment tools designed in a given culture or country may be appropriately used in another, particularly in undeveloped countries and regions where the cultural, social and economic contexts are quite different.

The interpretation of the outcomes of the studies included in this review and the assessment of the methodological and psychometric quality of each of the instruments showed that the MHLS has very good internal consistency, and that the MAKS has an acceptable internal consistency. On the other hand, the MHKQ demonstrated poor internal consistency in both primary studies in which it was used.

Considering the degree of reliability provided by the internal consistency, we can state that the MHLS is the instrument that demonstrates the best psychometric properties among all those included in this review. This evidence becomes even stronger when we realize that the authors who developed the instrument performed a testretest that confirmed its reliability. The MAKS showed good psychometric properties, as well. However, its reliability may be questioned given the time span between the first and the last administration of the assessment instrument. Even though there is only a five-year interval between 2009 and 2014, there are cultural, economic, social, and political issues that will certainly influence the way participants perceive and react to a given situation. Although the MHKQ has an acceptable degree of internal consistency compared to the others, it may probably obtain better psychometric properties if applied to other populations and contexts.

That way, the results obtained are in line with the systematic review of the literature conducted by Wei et al. (2016) that demonstrated that the MAKS and the MHLS have an excellent degree of content validity, the MHLS has a good degree of reliability, and the MAKS has an acceptable degree of reliability. The MHLS also shows an excellent internal consistency, while the MHKQ presents good internal consistency.

\section{CONCLUSION}

This integrative review of the literature identified three instruments used for assessing mental health literacy in selected primary studies that can be considered "quality studies" according to the criteria previously established. The outcomes produced confirm that the MHLS is the best validated assessment tool among those that are included in the corpus of this review. However, different assessment tools measure different properties, so, in addition to choosing the instrument which translates the best scientific evidence, the researcher should focus on choosing the one which best suits the population under study and ensure its cultural adaption and validation. A validated assessment instrument, in addition to helping to accurately measure the impact of the current mental health literacy interventions, is also important to guide the development of new interventions. 
Despite the evidence collected in this review, we are aware of its limitations. Given the diversity of unvalidated assessment tools administered to the population, it was difficult to retrieve a representative number of assessment instruments that would allow us to make consistent comparisons. In this sense, there is an urgent need to validate measures before their application and to conduct more advanced research, namely systematic reviews, to improve the existing scientific evidence. The gaps and limitations exist partly because the concept of mental health literacy is relatively recent. This means that the studies conducted so far to assess the knowledge about mental health literacy in adults using measurement instruments are still quite scarce.

\section{BIBLIOGRAPHIC REFERENCES}

Berkman, N. D., Sheridan, S. L., Donahue, K. E., Halpern, D. J., Viera, A., Crotty, K., Holland, A., Brasure, M., Lohr, K. N., Harden, E., Tant, E., Wallace, I., Viswanathan, M. (2011). Health Literacy Interventions and Outcomes: An Updated Systematic Review. Evidence Report/Technology Assesment No. 199. (Prepared by RTI International-University of North Carolina Evidence-based Practice Center under contract No. 290-200710056-I. AHRQ Publication Number 11-E006. Rockville, MD. Agency for Healthcare Research and Quality.

Carvalho, L. de F., Marin Rueda, F. J. (2016). Tipos e estratégias de avaliação. In C. Gorestein, Y. P. Wang, \& I. Hungerbühler (orgs.), Instrumentos de avaliação em saúde mental (Cap. 1.3, pp. 17-22). Porto Alegre: Artmed.

Gaino, L. V., Souza, J., Cirineu, C. Tiago, \& Tulimosky, T. D. (2018). 0 conceito de saúde mental para profissionais de saúde: um estudo transversal e qualitativo*. SMAD. Revista eletrônica saúde mental álcool e drogas, 14(2), 108-116. https://dx.doi.org/10.11606/issn.1806-6976.smad.2018.149449

Hansson, L., Stjernswärd, S \& Svensson, B. (2016). Changes in attitudes, intended behaviour, and mental health literacy in the Swedish population 2009-2014: na evaluation of a national antistigma programme. Acta Psychiatrica Scandinavic, 134(446), pp. 71-79. doi: 10.1111/acps.12609.

Higgins, J. P. T., Green, S. (Eds.) (2011). Cochrane handbook for systematic reviews of interventions: verison 5.1.0. London: The Cochrane Collaboration. Retrieved from http://www.cochrane.handbook.org

Jorm, A. F., Korten, A. E., Jacomb, P. A., Christensen, H., Rodgers, B. \& Pollitt, P. (1997). Mental health literacy: a survey of the public's ability to recognise mental disorders and their beliefs about the effectiveness of treatment. Medical Journal of Australia, 166(4), pp. 182-186.

Loureiro, L. M. J., Jorm, A. F., Rodrigues, M. A., Santos, J. C. P., Oliveira, R. A., Abrantes, A. R. D., ...Cardoso, D. F. B. (2014). Literacia em saúde mental - capacitar as pessoas e as comunidades para agir. Escola Superior de Enfermagem de Coimbra, Unidade de Investigação em Ciências da Saúde.

Marques, S., \& Lemos, S. (2017). Instrumentos de avaliação do letramento em saúde: revisão de literatura. Audiology - Communication Research, 22, e1757. Epub 24 de julho de 2017.https://dx.doi.org/10.1590/2317-6431-2016-1757

Mokkink, L. B., de Vet, H., Prinsen, C., Patrick, D. L., Alonso, J., Bouter, L. M., \& Terwee, C. B. (2018). COSMIN Risk of Bias checklist for systematic reviews of Patient-Reported Outcome Measures. Quality of life research: an international journal of quality-of-life aspects of treatment, care and rehabilitation, 27(5), 1171-1179. https://doi.org/10.1007/s11136-017-1765-4

National Assessment of Adult Literacy. (2003). Definition of literacy. Retrieved from http://nces.ed.gov/NAAl/fr_definition.asp

O'Connor, M. \& Casey, L. (2015). The Mental Health Literacy Scale (MHLS): A new scale-based measure of mental health literacy. Psychiatry Research. 229(1-2), pp. 511-516. doi: 10.1016/j.psychres.2015.05.064.

Page, M. J., McKenzie, J. E., Bossuyt, P. M., Boutron, I., Hoffmann, T. C., Mulrow, C. D., et al. (2021). The PRISMA 2020 statement: an updated guideline for reporting systematic reviews. BMJ 2021;372: n71. doi: 10.1136/bmj.n71 
Portugal, Ministério da Saúde, Direção Geral da Saúde. (2016). Perguntas e Respostas. Retrieved from https://www.dgs.pt/paginas-de-sistema/saude-de-a-a-z/programa-nacional-para-a-saude-mental/perguntas-e-respostas.aspx

Portugal, Ministério da Saúde, Direção Geral da Saúde. (2017b). Programa Nacional para a Saúde Mental. Lisboa: DGS.

Public Health England. (2015). Local action on health inequalities - Improving health literacy to reduce health inequalities. Retrieved from http://www.healthliteracyplace.org.uk/media/1239/hl-and-hi-ucl.pdf

Quartilho, J. M. (2010). Saúde Mental. Coimbra: Estado da Arte.

Stephenson, M., Riitano, D., Wilson, S., Leonardi-Bee, J., Mabire, C., Cooper, K., Monteiro da Cruz, D., MorenoCasbas, M. T., Lapkin, S. (2020). Chapter 12: Systematic reviews of measurement properties. In: Aromataris E, Munn Z (Editors). JBI Manual for Evidence Synthesis. JBI, 2020. Available from https://synthesismanual.jbi.global. https://doi.org/110.46658/JBIMES-20-13

The Joanna Briggs Institute. (2017). Critical Appraisal Checklist for Analytical Cross Sectional Studies. Retrieved from http://joannabriggs.org/assets/docs/critical-appraisal-tools/JBI_Critical_Appraisal-Checklist_for_ Analytical_Cross_Sectional_Studies2017.pdf

Varandas, T. \& Carneiro, A. V. (2006). Tipos de estudos clínicos. IV. Revisões sistemáticas. Revista Portuguesa de Cardiologia, 25(2), pp. 233-246.

Wang, J., He, Y., Jiang, Q., Cai, J., Wang, W., Zeng, Q., Miao, J., ... Zhang, M. (2013). Mental health literacy among residentes in Shanghai. Shanghai Archives of Psychiatry. 25(4), pp. 224-235. doi: 10.3969/j.issn.1002-0829.2013.04.004.

Wei, Y., McGrath, P., Hayden, J. \& Kutcher, S. (2016). Measurement properties of tools measuring mental health knowledge: a systemic review. BMC Psychiatry 16(297), pp. 1-16. doi: 10.1186/s12888-016-1012-5.

World Health Organization. (2014). In Mental Health: a state of well-being. Retrieved from http://www.who.int/features/factfiles/mental_health/en/

Yu, Y., Liu, Z., Hu, M., Liu, X., Liu, H., Yang, J., ... Xiao, S. (2015). Assessment of mental health literacy using a multifaceted measure among a Chinese rural population. BMJ Open, 5. doi: 10.1136/bmjopen-2015009054.

\section{Acknowledgements}

This work is funded by National Funds through the FCT - Foundation for Science and Technology, I.P., within the scope of the project Refa UIDB/05507/2020. Furthermore we would like to thank the Centre for Studies in Education and Innovation (CI\&DEI) and the Polytechnic of Viseu for their support. 
